\title{
Survival of infants treated with CKRT: comparing adapted adult platforms with the Carpediem ${ }^{\mathrm{Tm}}$
}

\author{
Stuart L. Goldstein ${ }^{1}$ (1) Enrico Vidal ${ }^{2} \cdot$ Zaccaria Ricci $^{3} \cdot$ Fabio Paglialonga $^{4} \cdot$ Licia Peruzzi $^{5} \cdot$ Mario Giordano $^{6}$. \\ Nicola Laforgia ${ }^{6} \cdot$ Claudio Ronco $^{7}$
}

Received: 25 April 2021 / Revised: 7 June 2021 / Accepted: 8 June 2021 / Published online: 20 August 2021

(C) IPNA 2021, corrected publication 2021

\begin{abstract}
Background The most severely ill neonates and infants with AKI who need kidney replacement therapy have had to rely upon peritoneal dialysis, or adaptations of veno-venous continuous kidney replacement therapy (CKRT) devices for adults. Data from the Prospective Pediatric CRRT (ppCRRT) registry observed children $<10 \mathrm{~kg}$ had a lower survival rate than children $>10 \mathrm{~kg}$ (44\% vs. $64 \%, \mathrm{p}<0.001$ ). A CKRT device designed specifically for small children could improve outcomes. The Cardio-Renal Pediatric Dialysis Emergency Machine (CARPEDIEM ${ }^{\mathrm{TM}}$ ) is specifically dedicated to providing CKRT for newborns and small infants.

Methods We performed a retrospective cohort analysis comparing patient severity of illness and outcomes between the ppCRRT and CARPEDIEM registries, involving 6 Italian pediatric intensive care units. Thirty-eight subjects from the CARPEDIEM registry and 84 subjects from the ppCRRT registry $<10 \mathrm{~kg}$ were screened for comparison. We compared patient outcomes with a weight-matched cohort $(<5 \mathrm{~kg})$ of 34 patients from the CARPEDIEM registry and 48 patients from the ppCRRT registry.

Results The ppCRRT subjects had higher rates of vasoactive medication at CKRT initiation. Survival to CKRT termination was higher for CARPEDIEM subjects $(33 / 34$ vs. $21 / 48, p<0.0001)$. Multivariable logistic regression showed that CARPEDIEM registry cohort was the only variable to retain an association with survival to CKRT discontinuation.

Conclusions We suggest children receiving CKRT using CARPEDIEM have excellent survival. Our data should be interpreted with caution given the retrospective comparison across two eras more than a decade apart.
\end{abstract}

Keywords Acute kidney injury $\cdot$ Neonates $\cdot$ Continuous kidney replacement therapy $\cdot$ Infant dialysis

Stuart L. Goldstein

tuart.goldstein@cchmc.org

1 Cincinnati Children's Hospital, 3333 Burnet Avenue, MLC 7022, Cincinnati, OH 45229, USA

2 University Hospital of Padova, Via Nicolò Giustiniani, 2, 35128 Padova, PD, Italy

3 Azienda Ospedaliero, Universitaria Meyer, Viale Gaetano Pieraccini, 24, 50139 Firenze, FI, Italy

4 Fondazione IRCSS Ca' Grande Ospedale Maggiore Policlinico, Via della Commenda, 10, 20122 Milano, MI, Italy

5 Regina Margherita Children's Hospital, Piazza Polonia, 94, 10126 Torino, TO, Italy

6 Giovanni XXIII Children's Hospital, Via Giovanni Amendola, 207, 70126 Bari, BA, Italy

7 San Bortolo Hospital, Viale Ferdinando Rodolfi, 37, 36100 Vicenza, VI, Italy

\section{Introduction}

The increase in the incidence of acute kidney injury (AKI) and association with poor outcomes in the general population has led to a call for action to make an early diagnosis, institute new preventive measures, and implement new therapies in order to improve clinical outcomes [1]. In fact, over the past two decades, an increased focus on AKI has occurred in adult patients and to a lesser extent in children, with the development of standardized AKI classification systems [2-6], multicenter large scale studies of epidemiology and outcomes [7, 8], assessment of novel AKI biomarkers $[9,10]$, and recognition of the association between AKI and the development of chronic kidney disease [11, 12].

Until recently, however, such progress had not been made for infants and neonates [13]. A robust assessment of neonatal AKI in over 2000 patients in the multicenter retrospective Assessment of Worldwide Acute Kidney Epidemiology in Neonates (AWAKEN) study revealed a $30 \%$ incidence of 
AKI [14]. Furthermore, neonates with stage 2 or 3 AKI by a neonatal modification of the Kidney Disease Improving Global Outcomes (KDIGO) criteria $[4,15]$ experienced a four times increased risk of mortality. The prospective Recombinant Erythropoietin for Protection of Infant Renal Disease (REPaIReD) study of extremely low gestational age neonates observed a $38 \%$ rate of AKI in over 900 patients [16]. Thus, critically ill neonates, just like older children and adults admitted to an ICU, have high rates of AKI.

Current continuous kidney replacement therapy (CKRT) technology has been adapted for use to support neonates and infants [17-19] for the past three decades. Although these adaptations have been associated with $30-40 \%$ survival rates in children $<10 \mathrm{~kg}$, data from the Prospective Pediatric Continuous Renal Replacement Therapy (ppCRRT) registry observed a lower survival rate in children $<10 \mathrm{~kg}$ with respect to those $>10 \mathrm{~kg}(44 \%$ vs. $64 \%, \mathrm{p}<0.001)$ [19]. Given the high rate of neonatal AKI and associated morbidity and mortality, the availability of a device designed specifically to address the unique challenges of supporting critically ill neonates and infants with CKRT (e.g., low blood volumes, accurate low blood pump and replacement/dialysis pump rates, extremely accurate scales) has the potential to improve outcomes.

The platform for CKRT called Cardio-Renal Pediatric Dialysis Emergency Machine (CARPEDIEM ${ }^{\mathrm{TM}}$; BellcoMedtronic, Mirandola, Italy) is a combination of hardware, software, and a disposable circuit specifically dedicated for newborns and small infants in a weight range of $2.5-9.9 \mathrm{~kg}$ with a BSA 0.15 to $0.5 \mathrm{~m}^{2}$ [20]. Three configurations are available with filters of different surface areas to adjust for patient size $\left(0.075,0.15\right.$ and $\left.0.25 \mathrm{~m}^{2}\right)$. The machine can perform continuous veno-venous hemofiltration $(\mathrm{CVVH})$ in preor post-dilution configuration and continuous veno-venous hemodialysis (CVVHD). We previously reported the first CARPEDIEM human use case [21], CARPEDIEM CKRT clearance characteristics [22], and a six center-experience using the CARPEDIEM with CVVH [23] and CVVHD [24]. We now report data from the multicenter Italian Registry of the CARPEDIEM using either CVVH or CVVHD, which update the previous reports with patientspecific outcome data. These data were used to support the application to the US Food and Drug Administration (FDA) that resulted in approval for marketing CARPEDIEM in the USA. In the current report and in the FDA application, we compared patient outcomes with a weight-matched cohort from the ppCRRT registry.

\section{Methods}

This was a retrospective cohort analysis of all infants and children who were supported with CARPEDIEM as part of their standard of clinical care from June 2013 through May 2018 at the following six Italian centers: University Hospital of Padua, Padua, Bambino Gesù Children's Hospital, Rome, Fondazione IRCSS Ca' Granda Ospedale Maggiore Policlinico, Milan, Giovanni XXIII Children's Hospital, Bari, San Bortolo Hospital, Vicenza, and Regina Margherita Children's Hospital, Turin. Clinicians were able to freely choose the treatment modality and characteristics based on local institutional practice and experience for: timing and criteria for treatment initiation, termination, and prescription, particularly since there is little or no consensus and scarce supporting literature regarding best practice. Patients were included after informed consent was obtained from the patient's legal representative and/or ethics committee approval from the Institutional Review Boards (IRB) of each of the institutions for retrospective data retrieval was received. The respective IRB Boards and approval numbers are listed in Supplemental Table 1.

The ppCRRT registry enrolled patients from 13 US centers from January 2001 through June 2005.

\section{Data collected}

Data including subject demographics, vascular access, and CKRT treatment parameters were collected using standardized case report forms. The Pediatric Risk Mortality (PRISM) II score was calculated for each patient at ICU admission to assess patient illness severity [25], since the PRISM II score was used to assess illness severity in patients from the ppCRRT registry. Percent fluid overload (\%FO) was determined from the time of ICU admission to the time of CKRT initiation as has been standard in pediatric CKRT studies [26]:

$\% \mathrm{FO}=[$ Fluid input (liters)-Fluid output (liters) $] /$ ICU admit weight $(\mathrm{kg}) * 100 \%$

Subject urine output was assessed in average $\mathrm{ml} / \mathrm{kg}$ of body weight per hour for the $24 \mathrm{~h}$ prior to CKRT initiation. Baseline kidney function was assessed by estimated glomerular filtration rate (eGFR) using the bedside Schwartz formula [27]. Adverse events and cause of death were not collected systematically in the ppCRRT registry. However, we did collect information regarding the cause of death (from death summaries) and days from CKRT discontinuation to subject death in non-surviving subjects in the CARPEDIEM registry.

\section{Statistical analysis}

For the current analysis, we only report the subject-related demographics and outcomes. We extracted data from the Italian CARPEDIEM Registry and assessed subjects who were $<10 \mathrm{~kg}$ in body weight at the time of ICU admission, or if CKRT was provided outside the ICU $(n=2)$, at the time 
of hospital admission. We extracted data from the ppCRRT registry database for all subjects $<10 \mathrm{~kg}$ in body weight at the time of ICU admission. Aggregate demographic and CKRT treatment data are described by medians (IQR) given the data were not distributed symmetrically. Only four patients in the CARPEDIEM Registry weighed between 5 and $10 \mathrm{~kg}$ (all of whom survived), so we restricted comparative analyses of the two registries to patients $\leq 5 \mathrm{~kg}$, since smaller patients could have greater likelihood of mortality. Potential differences in demographic, CKRT treatment, and patient outcome data between the CARPEDIEM and ppCRRT registries were compared with the Kruskal-Wallis test or by chi-square analysis with the Fisher's exact test for categorical variables. Subjects in the ppCRRT registry often received CKRT for reasons other than AKI [28], so we performed a sensitivity analysis of subjects with AKI as an indication for CKRT and additional sensitivity analysis for patients who had 5 of the 7 primary conditions leading to CKRT in both registries. AKI was defined by the KDIGO criteria [4]. We also performed sensitivity analyses for subjects who received either invasive mechanical ventilation (IMV) or a continuous infusion of an intravenous vasoactive medication, as these interventions are independently associated with mortality in critically ill children [7]. The primary outcome was subject survival for CKRT discontinuation. The secondary outcome was survival to ICU discharge. Multivariate logistic regression models were created to determine the significance of registry cohort on survival to CKRT termination or ICU discharge and to adjust for other significant risk factors. Predictors were entered in multivariate models when the associated risk factor's $\alpha$ was $<0.15$ in univariate analysis. Statistical analysis was performed with Stata (Version 14, StataCorp, Inc. College Station, TX). A p value of $<0.05$ was statistically significant.

\section{Results}

The study inclusion flow diagrams for the CARPEDIEM and ppCRRT registries are depicted in Figs. 1 and 2, respectively. After exclusions for subject weight $>5 \mathrm{~kg}, 34$ subjects remained from the CARPEDIEM registry, and 48 subjects remained from the ppCRRT registry. Forty-three ppCRRT subjects received CKRT with the PrismaTM (Gambro, Inc. Lakewood, Colorado) and five ppCRRT subjects received CKRT with the BM-25 (Baxter Healthcare, Deerfield, IL).

\section{Patient demographics}

Table 1 displays the comparison of demographic variables at CKRT initiation between the two groups. Demographic data from the two registries showed no differences noted in severity of illness indicated by PRISM II scores at ICU admission. There were no differences in CKRT initiation values for serum creatinine, estimated glomerular filtration rate (eGFR), or urine output. More patients in the ppCRRT group received vasopressors at CKRT initiation. Children in the CARPEDIEM registry had been in the ICU for longer until CKRT initiation compared to the ppCRRT group. The sensitivity analysis comparing only subjects with AKI as an indication for starting CKRT between the two registries is depicted in Supplemental Table 2. The variables that differed between the two registries were the same as those for all subjects, with the exception that there was no difference in ICU days until CKRT initiation between the two registries.

The primary underlying disease categories leading to the need for CKRT in each registry are depicted in Fig. 3. A wide spectrum of disease categories was associated with the provision of CKRT in both registries, which we grouped into seven primary disease categories: cardiac, hepatic, renal, sepsis, oncology, pulmonary, and inborn error of metabolism (IEM) based on adjudication by the primary investigators in each registry. A similar proportion of children required CKRT for support in sepsis and kidney-related diseases, while more patients with cardiac-related AKI were treated in the CARPEDIEM group compared to the ppCRRT group. Inborn error of metabolism was more prevalent in the ppCRRT registry; however, taken together these primary disease category distributions did not differ between the two groups $(p=0.18)$. Five of the primary disease categories leading to CKRT initiation were present in both registries (cardiac, IEM, renal, sepsis, and pulmonary: CARPEDIEM, $\mathrm{n}=34$; and ppCRRT, $n=39$ ). The distribution of patients in each of these disease categories did not differ between the registries ( $p$ $=0.52$ ). The only differences between the registries within this common primary disease subset were a younger age (10 days), higher rate of vasopressor use, and a longer ICU stay prior to CKRT initiation in the CARPEDIEM registry (Supplemental Table 3).

\section{Subject outcomes}

Tables 2 and 3 contain subject survival rate comparisons. Survival rates to CKRT termination were lower for patients receiving IMV or a vasoactive medication when data from the registries were combined (Table 2). The survival rates to CKRT termination (Table 3 ) were higher in the CARPEDIEM registry vs. the ppCRRT registry (33/34 vs. $21 / 48, p<0.0001)$. Likewise, the survival rate to CKRT termination for subjects with AKI as an indication for CKRT initiation was higher in the CARPEDIEM group (25/26 vs. $15 / 24, p<0.0001)$. In a sensitivity analysis, survival rates to CKRT discontinuation were higher for CARPEDIEM vs. ppCRRT subjects who received IMV $(p<0.0001)$ or a vasoactive medication $(p=0.0001)$. Similarly, survival rates to CKRT discontinuation were higher for the CARPEDIEM group for subjects who received a vasoactive medication ( $p$ 
Fig. 1 Patient selection flow diagram for the six Italian center CARPEDIEM registry cohort

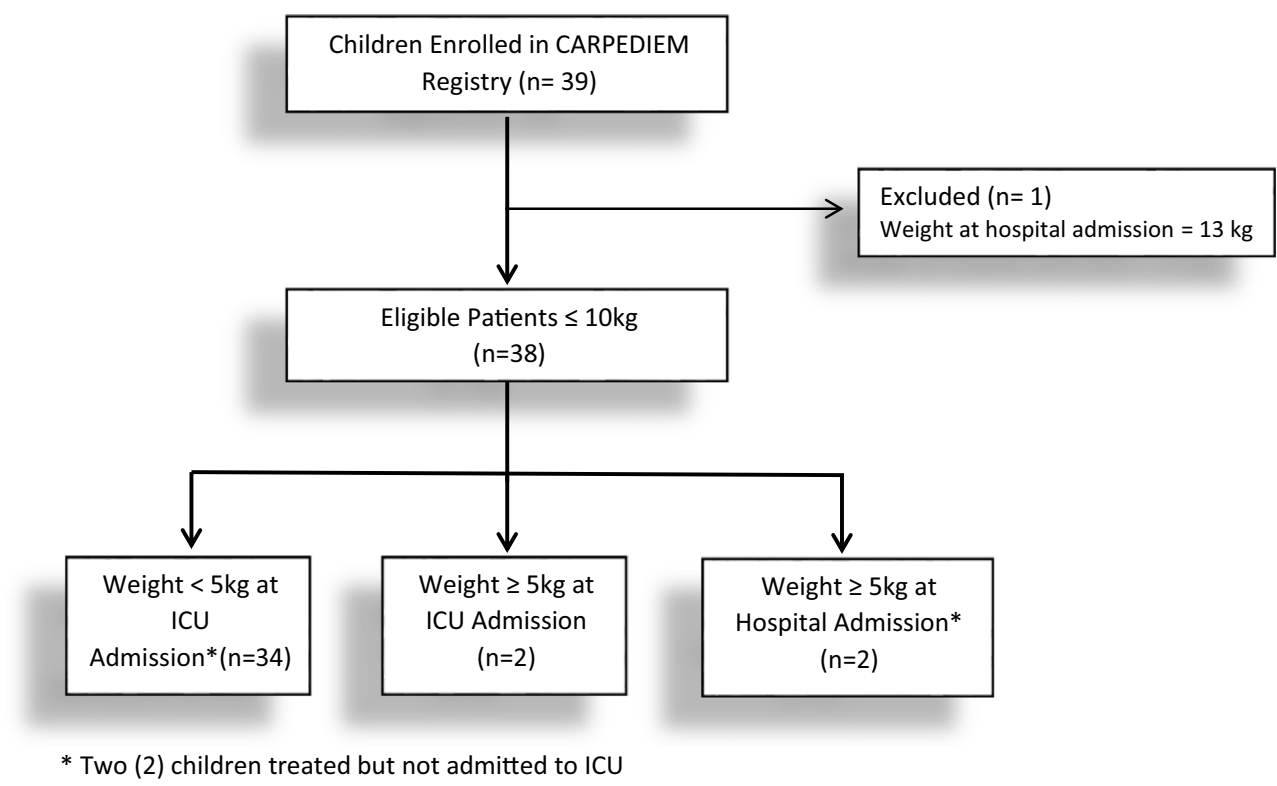

$=0.0001)$. Finally, survival rates were higher for the CARPEDIEM group in the restricted primary disease group of five primary diseases $(\mathrm{p}<0.0001)$.

The survival rates to ICU discharge (Table 3) did not differ for the CARPEDIEM vs. the ppCRRT registries (17/34 vs. $21 / 48, p=0.58)$, nor for subjects with AKI as an indication for CKRT initiation $(13 / 26$ vs. $14 / 34, p=0.60)$. Survival rates to ICU discharge did not differ between the registries for subjects who received IMV or a vasoactive medication. Survival rates to ICU discharge were no different between the CARPEDIEM and ppCRRT groups in the restricted primary disease group of five primary diseases.

A multivariable logistic regression model was created with the following variables having an $\alpha<0.15$ on univariate analysis in association with survival to CKRT discontinuation: subject weight (age excluded due to collinearity with weight), receipt of IMV, receipt of a vasoactive medication, $\% \mathrm{FO}$ at CKRT initiation, time to CKRT initiation, and registry cohort. Only the CARPEDIEM registry cohort retained an association with survival to CKRT discontinuation (OR 23.6 (95\% CI 2.5-225.7), $\mathrm{p}<0.006)$ ). Using the same variables to assess for associations with survival to ICU discharge, none were independently associated with survival. When the analysis was restricted to subjects from one of the five common primary disease categories, the CARPEDIEM registry cohort was still the only variable that retained an association with survival to CKRT discontinuation (OR 17.2 (95\% CI, 1.9$153.9 ; \mathrm{p}<0.01)$, but no variable was associated with survival
Fig. 2 Patient selection flow diagram for the Prospective Pediatric Continuous Renal Replacement Therapy (ppCRRT) registry cohort

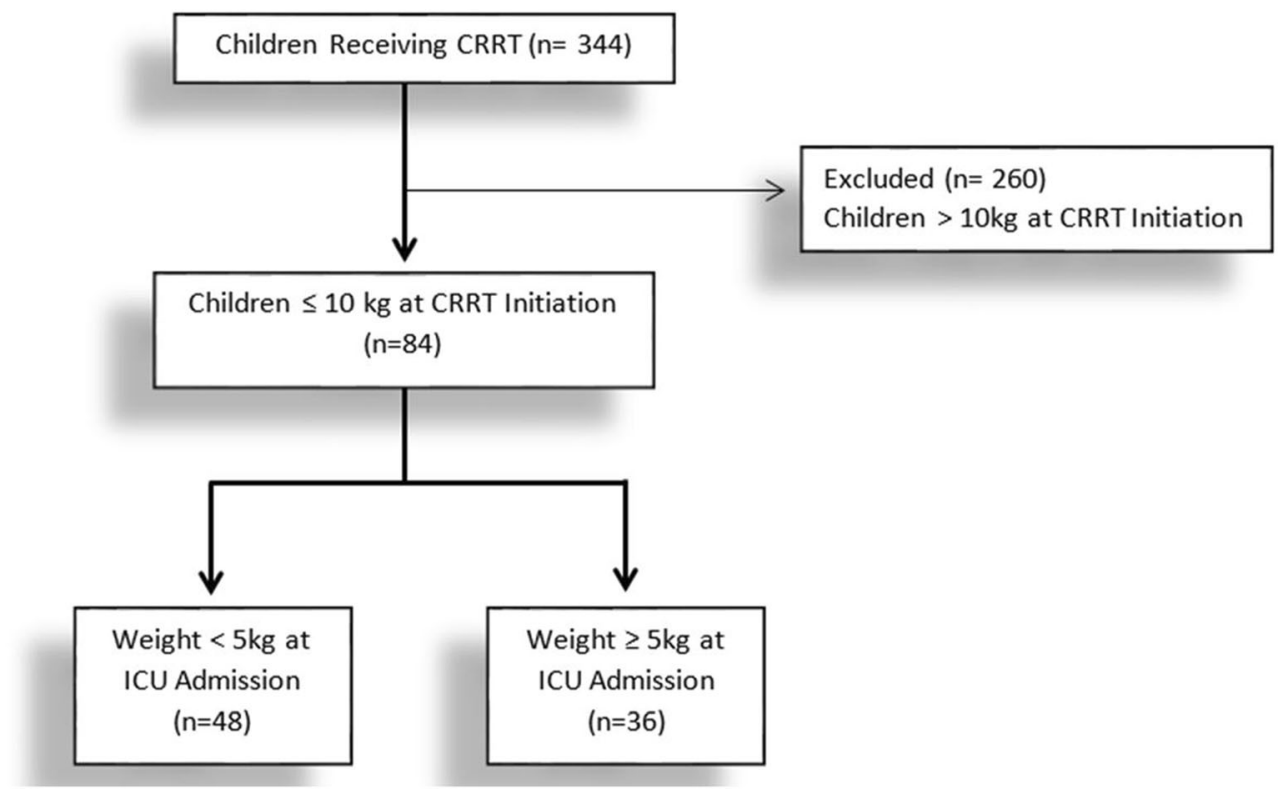


Table 1 Patient demographics at CKRT initiation

\begin{tabular}{|c|c|c|c|}
\hline \multirow[t]{2}{*}{ Characteristics } & \multicolumn{3}{|l|}{ Median [IQR] } \\
\hline & ppCRRT & CARPEDIEM & $\mathrm{p}$ value* \\
\hline Patient age at CKRT initiation (days) & $\begin{array}{l}\mathrm{n}=48 \\
20.0[6.0-56.0]\end{array}$ & $\begin{array}{l}\mathrm{n}=34 \\
12.5[7.0-32.0]\end{array}$ & 0.29 \\
\hline Male Gender n/N (\%) & $28 / 48(58)$ & $23 / 34(68)$ & 0.26 \\
\hline Weight (ICU admission) (kg) & $\begin{array}{l}\mathrm{n}=48 \\
3.2[2.7-3.8]\end{array}$ & $\begin{array}{l}\mathrm{n}=34 \\
2.8[2.2-3.5]\end{array}$ & 0.08 \\
\hline PRISM II score (ICU admission) & $\begin{array}{l}\mathrm{n}=40 \\
20.5[11.0-27.0]\end{array}$ & $\begin{array}{l}\mathrm{n}=33 \\
19[14.0-26.0]\end{array}$ & 0.62 \\
\hline Serum Creatinine (CKRT start) (mg/dL) & $\begin{array}{l}\mathrm{n}=48 \\
1.2[0.6-2.4)\end{array}$ & $\begin{array}{l}\mathrm{n}=32 \\
1.3[0.9-2.8]\end{array}$ & 0.34 \\
\hline $\mathrm{eGFR}^{\#}$ (CKRT start) $\left(\mathrm{ml} / \mathrm{min} / 1.73 \mathrm{~m}^{2}\right)$ & $\begin{array}{l}\mathrm{n}=42 \\
17.2[7.9-37.2]\end{array}$ & $\begin{array}{l}\mathrm{n}=32 \\
14.2[7.6-21.4]\end{array}$ & 0.38 \\
\hline Fluid overload (CKRT start) (\%) & $\begin{array}{l}\mathrm{n}=43 \\
16.0[1.7-40.9]\end{array}$ & $\begin{array}{l}\mathrm{n}=34 \\
9.5[0-23]\end{array}$ & 0.12 \\
\hline Urine output ( $24 \mathrm{~h}$ prior to CKRT start) $(\mathrm{ml} / \mathrm{kg} / \mathrm{h})$ & $\begin{array}{l}\mathrm{n}=41 \\
0.8[0.1-3.0]\end{array}$ & $\begin{array}{l}\mathrm{n}=31 \\
1.2[0.0-2.6]\end{array}$ & 0.97 \\
\hline Mechanical ventilation (CKRT start) n/N (\%) & $38 / 48(79)$ & $21 / 33(64)$ & 0.12 \\
\hline Vasopressor dependency (CKRT start) n/N (\%) & $37 / 48(77)$ & $10 / 33(30)$ & $<0.0001$ \\
\hline ICU stay prior to CKRT start (days) & $\begin{array}{l}\mathrm{n}=48 \\
1[0-8]\end{array}$ & $\begin{array}{l}\mathrm{n}=34 \\
7.0[1-13]\end{array}$ & 0.04 \\
\hline CKRT duration (days) & $\begin{array}{l}\mathrm{n}=48 \\
3[1-9]\end{array}$ & $\begin{array}{l}\mathrm{n}=34 \\
3.5[1-7]\end{array}$ & 0.82 \\
\hline
\end{tabular}

*Categorical $p$ value is based on a two-sided Fisher's exact test. Continuous p value is based on Kruskall-Wallis nonparametric test. [IQR] = Interquartile range, ${ }^{\#}$ eGFR calculated using the bedside Schwartz equation [27]

to ICU discharge. The results of the multivariable analyses are depicted in Tables 4, 5, 6, and 7.

Supplemental Table 4 contains relevant data regarding the outcomes of subjects in the CARPEDIEM registry who survived to CKRT discontinuation but not to ICU discharge. Subjects who did not survive to ICU discharge had a higher

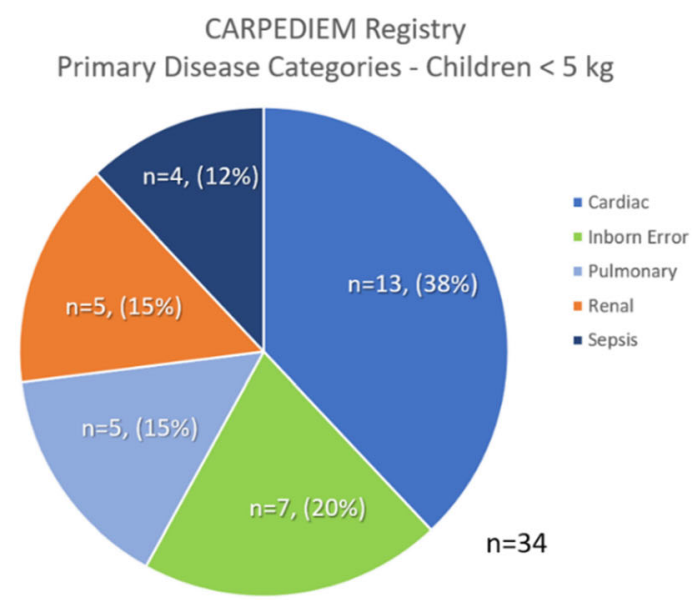

severity of illness compared to survivors in the CARPEDIEM cohort (median [IQR] 23 [29, 30] vs. $16.5[9,23], \mathrm{p}=0.01$ ). Most patients who did not survive from CKRT discontinuation to ICU discharge $(15 / 18)$ received at least two CKRT procedures and died at least two days after CKRT discontinuation $(13 / 18)$.

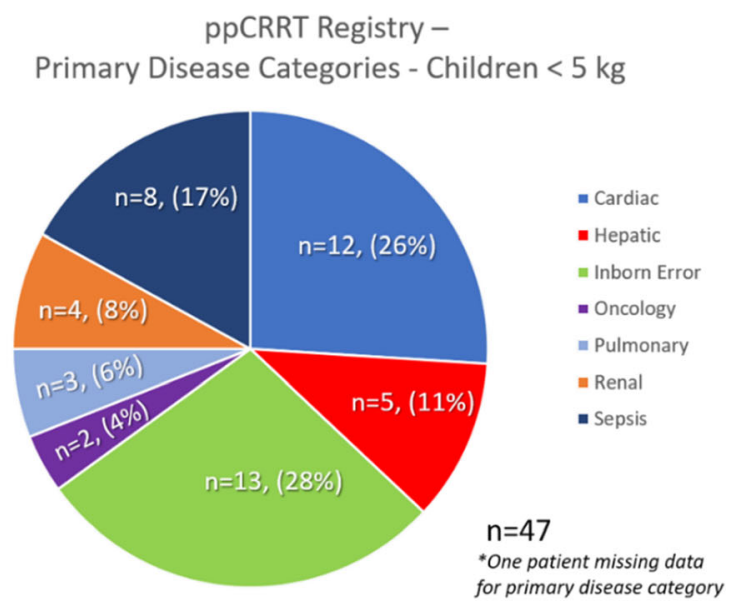

Fig. 3 The distribution of primary disease categories leading to the need for CKRT did not differ between the CARPEDIEM and ppCRRT registry cohorts 
Table 2 Subject outcome data for the combined registries

\begin{tabular}{lll} 
Subject description & & p-value* \\
\hline Survival to CKRT termination n/N (\%) & & $35 / 58(60)$ vs. $18 / 21(86)$ \\
Subjects receiving IMV vs. No IMV & $24 / 46(52)$ vs. $29 / 33(88)$ & 0.06 \\
Subjects receiving vasoactive medication vs. not & & 0.001 \\
Survival to ICU Discharge n/N (\%) & $26 / 58(45)$ vs. $13 / 20(65)$ & 0.19 \\
Subjects receiving IMV vs. No IMV & $20 / 45(44)$ vs. $19 / 33(58)$ & 0.36 \\
Subjects receiving vasoactive medication vs. not & \\
\hline
\end{tabular}

*Categorical p-value is based on a two-sided Fisher's exact test

\section{Discussion}

Provision of CKRT with CARPEDIEM was associated with better survival rates despite the small patient body weight and the high severity of illness. The CARPEDIEM subject outcomes compare favorably to a cohort from the ppCRRT registry matched for subject weight at the time of ICU admission. Although there were some differences in subject demographics between the two registries, the only potentially significant $(<0.15)$ patient-related differences were IMV, vasoactive medication use, and percent fluid overload at the time of CKRT initiation. The ppCRRT registry subjects were older (by 10 days) and started CKRT earlier in their ICU course. While ppCRRT registry subjects had higher rates of vasopressor and IMV use, PRISM II scores did not differ between the registries, suggesting that the patients had similar illness severity in each registry. Even if the higher vasopressor provision and IMV rates seen in the ppCRRT subjects reflect more complicated patients, this likely does not solely account for the much higher (97\%) survival rate seen in the CARPEDIEM registry. The sensitivity analysis comparing CARPEDIEM and ppCRRT patients who received a vasoactive medication or IMV or were restricted to five common primary diagnoses between the registries still showed higher survival rates in the CARPEDIEM patients. Furthermore, the multivariable logistic regression model demonstrated that CARPEDIEM was the only variable that retained a survival advantage. However, this observation should be interpreted with caution given the wide range of $95 \%$ confidence intervals.

Our data must also be interpreted with caution due to several limitations. First, the eras of the two registries are separated by over a decade in time (2001-2005 for ppCRRT and 2013-2018 for CARPEDIEM). It is conceivable that advancements in neonatal/pediatric intensive care could have accounted for improved survival in the more recent CARPEDIEM cohort. Advancements in non-CARPEDIEM CKRT technology have occurred since the ppCRRT registry era. Subjects in the ppCRRT registry were supported

Table 3 Outcome data comparison between the two registries for subjects $<5 \mathrm{~kg}$

\begin{tabular}{|c|c|c|c|}
\hline Subject description & ppCRRT & CARPEDIEM & $\mathrm{p}$ value* \\
\hline \multicolumn{4}{|l|}{ Survival to CKRT termination $\mathrm{n} / \mathrm{N}(\%)$} \\
\hline All subjects $<5 \mathrm{~kg}$ & $21 / 46(46)$ & $33 / 34(97)$ & $<0.0001$ \\
\hline Subjects with acute kidney injury & $15 / 34(44)$ & $25 / 26(96)$ & $<0.0001$ \\
\hline Subjects receiving invasive mechanical ventilation & $15 / 37(40)$ & $20 / 21(95)$ & $<0.0001$ \\
\hline Subjects receiving vasoactive medication & $14 / 36(39)$ & $10 / 10(100)$ & 0.0001 \\
\hline Restricted to primary diseases in both registries & $19 / 39(49)$ & $33 / 34(97)$ & $<0.0001$ \\
\hline Survival to ICU Discharge n/N (\%) & ppCRRT & CARPEDIEM & $\mathrm{p}$ value* \\
\hline All subjects $<5 \mathrm{~kg}$ & $21 / 48(44)$ & $17 / 34(50)$ & 0.58 \\
\hline Subjects with acute kidney injury & $14 / 34(41)$ & $13 / 26(50)$ & 0.60 \\
\hline Subjects receiving invasive mechanical ventilation & $15 / 37(40)$ & $11 / 21(52)$ & 0.42 \\
\hline Subjects receiving vasoactive medication & $14 / 35(39)$ & $6 / 10(60)$ & 0.30 \\
\hline Restricted to primary diseases in both registries & $20 / 38(53)$ & $18 / 34(53)$ & 1.0 \\
\hline
\end{tabular}

*Categorical $\mathrm{p}$ value is based on a two-sided Fisher's exact test 
Table 4 Multivariable analyses. Survival to CKRT discontinuation

\begin{tabular}{|c|c|c|}
\hline Variable & OR $(95 \% \mathrm{CI})$ & $\mathrm{p}$ value \\
\hline Registry (CARPEDIEM) & $23.6(2.5-225.7)$ & 0.005 \\
\hline Weight at ICU Admit (kg) & $0.98(0.82-1.18)$ & 0.82 \\
\hline $\begin{array}{l}\text { Received vasoactive } \\
\text { medication (yes) }\end{array}$ & $1.03(0.35-3.04)$ & 0.95 \\
\hline Received IMV (yes) & $0.42(0.11-1.58)$ & 0.20 \\
\hline Fluid overload at CKRT initiation (\%) & $0.99(0.97-1.00)$ & 0.13 \\
\hline $\begin{array}{l}\text { Time from ICU admission to } \\
\text { CKRT initiation (days) }\end{array}$ & $1.00(0.99-1.01)$ & 0.81 \\
\hline
\end{tabular}

predominantly with the Prisma ${ }^{\mathrm{TM}}$ platform (Gambro Renal Products); other earlier generation platforms such as the BM-25 ${ }^{\mathrm{TM}}$ (Baxter Healthcare) were used by one center. In the ensuing years, the Prismaflex ${ }^{\mathrm{TM}}$ (Gambro, then Baxter) platform has been used widely, and a smaller filter, the HF $20^{\mathrm{TM}}$ has been used for patients $8-20 \mathrm{~kg}[30,31]$. It should be noted that the HF20 ${ }^{\mathrm{TM}}$ filter has only recently been available for use in the USA under an emergency use authorization from the US FDA during the COVID-19 pandemic. Also, while the Aquadex ${ }^{\mathrm{TM}}$ platform (CHF Solutions, Inc.) has been adapted to provide CVVH to neonates and infants [17], the replacement fluid must currently be given via an external pump not integrated into the circuit, so special protocols are required to provide adequate vigilance for patient safety. On the other hand, some aspects may have affected the outcomes with the novel technology: several CARPEDIEM software and hardware updates have been provided along the study period, which have had some impact on overall outcomes (e.g., flow rate accuracy improvement, resolution of technical bugs). Finally, use of serum creatinine to estimate GFR is problematic in this study, since for many subjects serum creatinine reflects maternal creatinine. In addition, GFR maturation is likely ongoing in this age group. So, we interpret that lack of eGFR difference between the two registries with caution.

Finally, it is conceivable that ICU and CKRT practice patterns differ between Italy and the USA, and these were not captured by either registry. To that end, it is important

Table 5 Multivariable analyses. Survival to ICU discharge

\begin{tabular}{lll}
\hline Variable & OR (95\% CI) & p value \\
\hline Registry (CARPEDIEM) & $1.14(0.44-2.99)$ & 0.78 \\
Weight at ICU Admit (kg) & $0.98(0.83-1.16)$ & 0.82 \\
$\begin{array}{l}\text { Received vasoactive } \\
\text { medication (yes) }\end{array}$ & $0.90(0.36-2.24)$ & 0.95 \\
$\begin{array}{l}\text { Received IMV (yes) } \\
\text { Fluid overload at CKRT initiation (\%) }\end{array}$ & $0.55(0.20-1.54)$ & 0.20 \\
$\begin{array}{l}\text { Time from ICU admission to } \\
\quad \text { CKRT initiation (days) }\end{array}$ & $1.00(0.97-1.01)$ & 0.05 \\
\hline & & 0.99 \\
\hline
\end{tabular}

Table 6 Multivariable analyses. Survival to CKRT discontinuation in patients with five common underlying disease categories

\begin{tabular}{lll}
\hline Variable & OR (95\% CI) & p value \\
\hline Registry (CARPEDIEM) & $17.2(1.9-153.9)$ & 0.01 \\
Weight at ICU Admit (kg) & $0.99(0.81-1.20)$ & 0.90 \\
$\begin{array}{l}\text { Received vasoactive } \\
\quad \text { medication (yes) }\end{array}$ & $0.84(0.24-2.90)$ & 0.78 \\
$\begin{array}{l}\text { Received IMV (yes) } \\
\text { Fluid overload at CKRT initiation (\%) }\end{array}$ & $0.63(0.15-2.67)$ & 0.53 \\
$\begin{array}{l}\text { Time from ICU admission to } \\
\quad \text { CKRT initiation (days) }\end{array}$ & $0.98(0.97-1.01)$ & 0.26 \\
& & 0.31 \\
\hline
\end{tabular}

to note that no difference in subject survival to ICU discharge was observed between the groups, which begs the question as to whether CKRT discontinuation practices differ between the countries, with CKRT termination occurring earlier in Italy. If true, it could be that the nearly $100 \%$ survival to CKRT discontinuation in the CARPEDIEM cohort resulted from a bias towards earlier termination. However, we did not see a difference in CKRT duration between the two groups. We also speculate that the choice of initiating later and terminating earlier in the Italian cohort may be partially due to some inexperience in the application of the novel technology. Review of the causes of death and our observations that patients who did not survive from CKRT discontinuation to ICU discharge received at least two treatments with the CARPEDIEM and died at least 2 days after CKRT discontinuation. We suggest, therefore, that underlying illness and other non-AKI, non-CKRT-related factors influenced ICU survival. Given the small heterogenous population and the multiplicity of clinical factors that confound ICU mortality, a larger (and possibly more homogenous) population should be observed in order to verify if the trend in slightly better survival (50 vs. $42 \%$ ) in the CARPEDIEM cohort persists. Finally, the retrospective interrogation of both registries and the lack of prospective collection of adverse events could have introduced unintended bias in the comparisons.

Table 7 Multivariable analyses. Survival to ICU discharge in patients with five common underlying disease categories

\begin{tabular}{lll}
\hline Variable & OR (95\% CI) & p value \\
\hline Registry (CARPEDIEM) & $1.31(0.43-3.98)$ & 0.64 \\
Weight at ICU Admit (kg) & $0.97(0.80-1.16)$ & 0.73 \\
Received vasoactive medication (yes) & $0.91(0.32-2.62)$ & 0.86 \\
Received IMV (yes) & $0.70(0.22-2.21)$ & 0.53 \\
Fluid overload at CKRT initiation (\%) & $0.99(0.97-1.01)$ & 0.27 \\
Time from ICU admission to & $0.93(0.86-1.00)$ & 0.05 \\
$\quad$ CKRT initiation (days) & & \\
\hline
\end{tabular}


Supplementary Information The online version contains supplementary material available at https://doi.org/10.1007/s00467-021-05180-y.

Acknowledgements The authors would like to acknowledge Amy Roettger, RN, Mary Lou Wratten PhD, and Silvia Manfredini from Bellco-Medtronic for their assistance in coordinating data capture from the clinical sites.

\section{Declarations}

Conflict of interest Dr. Goldstein serves as a paid consultant to BellcoMedtronic to support the CARPEDIEM application to the FDA for a marketing approval in the USA. Dr. Goldstein performed all statistical analyses for that application and the current manuscript and did not receive fees for the development of this manuscript. Bellco-Medtronic had no influence on the data analyses performed, nor did Bello-Medtronic have access to the raw data at any time during the FDA application process or the development of this manuscript.

\section{References}

1. (2005) American Society of Nephrology Renal Research Report. J Am Soc Nephrol 16:1886-1903

2. Bellomo R, Ronco C, Kellum JA, Mehta RL, Palevsky P (2004) Acute renal failure - definition, outcome measures, animal models, fluid therapy and information technology needs: the Second International Consensus Conference of the Acute Dialysis Quality Initiative (ADQI) Group. Crit Care 8:R204-R212

3. Mehta RL, Kellum JA, Shah SV, Molitoris BA, Ronco C, Warnock DG, Levin A (2007) Acute kidney injury network: report of an initiative to improve outcomes in acute kidney injury. Crit Care 11:R31

4. (2012) Kidney disease: improving global outcomes (KDIGO) Acute kidney injury work group - KDIGO clinical practice guideline for acute kidney injury. Kidney Int suppl:1-138

5. Blinder JJ, Goldstein SL, Lee VV, Baycroft A, Fraser CD, Nelson D, Jefferies JL (2012) Congenital heart surgery in infants: effects of acute kidney injury on outcomes. J Thorac Cardiovasc Surg 143: 368-374

6. Akcan-Arikan A, Zappitelli M, Loftis LL, Washburn KK, Jefferson LS, Goldstein SL (2007) Modified RIFLE criteria in critically ill children with acute kidney injury. Kidney Int 71:1028-1035

7. Kaddourah A, Basu RK, Bagshaw SM, Goldstein SL (2017) Epidemiology of acute kidney injury in critically Ill children and young adults. N Engl J Med 376:11-20

8. Hoste EA, Bagshaw SM, Bellomo R, Cely CM, Colman R, Cruz DN, Edipidis K, Forni LG, Gomersall CD, Govil D, Honore PM, Joannes-Boyau O, Joannidis M, Korhonen AM, Lavrentieva A, Mehta RL, Palevsky P, Roessler E, Ronco C, Uchino S, Vazquez JA, Vidal Andrade E, Webb S, Kellum JA (2015) Epidemiology of acute kidney injury in critically ill patients: the multinational AKIEPI study. Intensive Care Med 41:1411-1423

9. Waikar SS, Bonventre JV (2008) Biomarkers for the diagnosis of acute kidney injury. Nephron Clin Pract 109:c192-c197

10. Devarajan P (2007) Emerging biomarkers of acute kidney injury. Contrib Nephrol 156:203-212

11. Chawla LS, Amdur RL, Amodeo S, Kimmel PL, Palant CE (2011) The severity of acute kidney injury predicts progression to chronic kidney disease. Kidney Int 79:1361-1369

12. Madsen NL, Goldstein SL, Froslev T, Christiansen CF, Olsen M (2017) Cardiac surgery in patients with congenital heart disease is associated with acute kidney injury and the risk of chronic kidney disease. Kidney Int 92:751-756
13. Askenazi DJ, Ambalavanan N, Goldstein SL (2009) Acute kidney injury in critically ill newborns: what do we know? What do we need to learn? Pediatr Nephrol 24:265-274

14. Jetton JG, Boohaker LJ, Sethi SK, Wazir S, Rohatgi S, Soranno DE, Chishti AS, Woroniecki R, Mammen C, Swanson JR, Sridhar S, Wong CS, Kupferman JC, Griffin RL, Askenazi DJ, Neonatal Kidney Collaborative (NKC) (2017) Incidence and outcomes of neonatal acute kidney injury (AWAKEN): a multicentre, multinational, observational cohort study. Lancet Child Adolesc Health 1: 184-194

15. Askenazi D, Abitbol C, Boohaker L, Griffin R, Raina R, Dower J, Davis TK, Ray PE, Perazzo S, DeFreitas M, Milner L, Ambalavanan N, Cole FS, Rademacher E, Zappitelli M, Mhanna M, Neonatal Kidney Collaborative (2019) Optimizing the AKI definition during first postnatal week using assessment of worldwide acute kidney injury epidemiology in neonates (AWAKEN) cohort. Pediatr Res 85:329-338

16. Askenazi DJ, Heagerty PJ, Schmicker RH, Griffin R, Brophy P, Juul SE, Mayock DE, Goldstein SL, Hingorani S, PENUT Trial Consortium (2020) Prevalence of acute kidney injury (AKI) in extremely low gestational age neonates (ELGAN). Pediatr Nephrol 35:1737-1748

17. Menon S, Broderick J, Munshi R, Dill L, DePaoli B, FathallahShaykh S, Claes D, Goldstein SL, Askenazi DJ (2019) Kidney support in children using an ultrafiltration device: a multicenter, retrospective study. Clin J Am Soc Nephrol 14:1432-1440

18. Symons JM, Brophy PD, Gregory MJ, McAfee N, Somers MJ, Bunchman TE, Goldstein SL (2003) Continuous renal replacement therapy in children up to $10 \mathrm{~kg}$. Am J Kidney Dis 41:984-989

19. Askenazi DJ, Goldstein SL, Koralkar R, Fortenberry J, Baum M, Hackbarth R, Blowey D, Bunchman TE, Brophy PD, Symons J, Chua A, Flores F, Somers MJ (2013) Continuous renal replacement therapy for children $</=10 \mathrm{~kg}$ : a report from the prospective pediatric continuous renal replacement therapy registry. J Pediatr 162(587-592): 5583

20. Ronco C, Garzotto F, Ricci Z (2012) CA.R.PE.DI.E.M. (Cardiorenal pediatric dialysis emergency machine): evolution of continuous renal replacement therapies in infants. A personal journey. Pediatr Nephrol 27:1203-1211

21. Ronco C, Garzotto F, Brendolan A, Zanella M, Bellettato M, Vedovato S, Chiarenza F, Ricci Z, Goldstein SL (2014) Continuous renal replacement therapy in neonates and small infants: development and first-in-human use of a miniaturised machine (CARPEDIEM). Lancet 383:1807-1813

22. Lorenzin A, Garzotto F, Alghisi A, Neri M, Galeano D, Aresu S, Pani A, Vidal E, Ricci Z, Murer L, Goldstein SL, Ronco C (2016) CVVHD treatment with CARPEDIEM: small solute clearance at different blood and dialysate flows with three different surface area filter configurations. Pediatr Nephrol 31:1659-1665

23. Garzotto F, Vidal E, Ricci Z, Paglialonga F, Giordano M, Laforgia N, Peruzzi L, Bellettato M, Murer L, Ronco C (2020) Continuous kidney replacement therapy in critically ill neonates and infants: a retrospective analysis of clinical results with a dedicated device. Pediatr Nephrol 35:1699-1705

24. Vidal E, Cocchi E, Paglialonga F, Ricci Z, Garzotto F, Peruzzi L, Murer L, Ronco C (2019) Continuous veno-venous hemodialysis using the cardio-renal pediatric dialysis emergency machine TM: First Clinical Experiences. Blood Purif 47:149-155

25. Pollack MM, Ruttimann UE, Getson PR (1988) Pediatric risk of mortality (PRISM) score. Crit Care Med 16:1110-1116

26. Sutherland SM, Zappitelli M, Alexander SR, Chua AN, Brophy PD, Bunchman TE, Hackbarth R, Somers MJ, Baum M, Symons JM, Flores FX, Benfield M, Askenazi D, Chand D, Fortenberry JD, Mahan JD, McBryde K, Blowey D, Goldstein SL (2010) Fluid overload and mortality in children receiving continuous renal 
replacement therapy: the prospective pediatric continuous renal replacement therapy registry. Am J Kidney Dis 55:316-325

27. Schwartz GJ, Munoz A, Schneider MF, Mak RH, Kaskel F, Warady BA, Furth SL (2009) New equations to estimate GFR in children with CKD. J Am Soc Nephrol 20:629-637

28. Fleming GM, Walters S, Goldstein SL, Alexander SR, Baum MA, Blowey DL, Bunchman TE, Chua AN, Fletcher SA, Flores FX, Fortenberry JD, Hackbarth R, McBryde K, Somers MJ, Symons JM, Brophy PD (2012) Nonrenal indications for continuous renal replacement therapy: a report from the prospective pediatric continuous renal replacement therapy registry group. Pediatr Crit Care Med 13:e299-e304

29. Koralkar R, Ambalavanan N, Levitan EB, McGwin G, Goldstein S, Askenazi D (2011) Acute kidney injury reduces survival in very low birth weight infants. Pediatr Res 69:354-358
30. Munshi R, Lee-Son K, Hackbarth RM, Quigley R, Sutherland SM, Echeverri J, Goldstein SL (2020) Clinical evaluation of the Prismaflex HF 20 set and Prismaflex system 7.10 for acute continuous kidney replacement therapy (CKRT) in children. Pediatr Nephrol 35:2345-2352

31. Rodl S, Marschitz I, Mache CJ, Koestenberger M, Madler G, Zobel G (2011) Continuous renal replacement therapy with Prismaflex HF20 disposable set in children from 4 to $15 \mathrm{~kg}$. ASAIO J 57: $451-455$

32. Hsu CW, Symons JM (2010) Acute kidney injury: can we improve prognosis? Pediatr Nephrol 25:2401-2412

Publisher's note Springer Nature remains neutral with regard to jurisdictional claims in published maps and institutional affiliations. 